\title{
NOWE GATUNKI WE FLORZE MCHÓW WIGIERSKIEGO PARKU NARODOWEGO
}

\section{NEW SPECIES IN THE MOSS FLORA OF THE WIGRY NATIONAL PARK}

\author{
Monika Staniaszek-Kik, Piotr Górski, WiesŁaw FaŁtynowicz, Hanna FaŁtynowicz, \\ Marek Halama, Agnieszka Kowalewska, Katarzyna Patejuk, Bartosz Pencakowski, \\ Amelia Piegdoń, Maciej Romański
}

H. Fałtynowicz, Katedra Zaawansowanych Technologii Materiałowych, Politechnika Wrocławska, ul. Gdańska 7/9, 50-344 Wrocław, Poland, e-mail: hanna.faltynowicz@pwr.edu.pl

W. Fałtynowicz, Zakład Botaniki, Uniwersytet Wrocławski, ul. Kanonia 6/8, 50-328 Wrocław, Poland, e-mail: oenothera8@wp.pl

P. Górski, Katedra Botaniki, Uniwersytet Przyrodniczy w Poznaniu, ul. Wojska Polskiego 71 C, 60-625 Poznań, Poland, e-mail: piotr.gorski@up.poznan.pl

M. Halama, Muzeum Przyrodnicze, Uniwersytet Wrocławski, ul. Sienkiewicza 5, 50-335, Wrocław, Poland, e-mail: marek.halama@uwr.edu.pl

A. Kowalewska, Pomorski Zespół Parków Krajobrazowych w Słupsku, Oddział Zespołu w Gdańsku, Trójmiejski Park Krajobrazowy, ul. Polanki 51, 80-308 Gdańsk, Poland, e-mail: a.kowalewska@pomorskieparki.pl

K. Patejuk, Katedra Ochrony Roślin, Uniwersytet Przyrodniczy we Wrocławiu, Plac Grunwaldzki 24a, 50-363 Wrocław, Poland, e-mail: katarzyna.patejuk@upwr.edu.pl

B. Pencakowski, Zakład Biotechnologii Farmaceutycznej, Katedra Biologii i Botaniki Farmaceutycznej, Uniwersytet Medyczny we Wrocławiu, ul. Borowska 211 A, 50-556 Wrocław, Poland e-mail: bartosz.pencakowski@umed.wroc.pl

A. Piegdoń, Biuro Urządzania Lasu i Geodezji Leśnej Oddział w Przemyślu, ul. Wysockiego 46a, 37-700 Przemyśl, Poland, e-mail: amelia.piegdon@onet.pl

M. Romański, Wigierski Park Narodowy, Krzywe 82, 16-402 Suwałki, Poland, e-mail: maciej.romanski@wigry.org.pl

M. Staniaszek-Kik, Katedra Geobotaniki i Ekologii Roślin, Wydział Biologii i Ochrony Środowiska, Uniwersytet Łódzki, ul. Banacha 12/16, 90-237 Łódź, Poland, e-mail: kik@biol.uni.lodz.pl

AвSTRACT. In the years 2017-2019 bryological investigations were carried out in the Wigierski National Park. As a result, five moss species new to this area have been found - Dicranoweisia cirrata, Homomallium incurvatum, Orthotrichum pulchellum, Serpoleskea subtilis and Zygodon rupestris. The paper provides information about their localities and habitats.

Key wORDs: mszaki, epifity, korony drzew, Quercus robur, Populus tremula, Acer pseudoplatanus, Picea abies

\section{WSTĘP}

Wigierski Park Narodowy jest położony w północno-wschodniej części Polski, na skraju Puszczy Augustowskiej - jednego z największych, zwartych kompleksów leśnych na niżu Europy (KRzYszTofiak 2010). Park został utworzony w celu ochrony zespołu jezior, rzek i związanych z nimi siedlisk wodno-błotnych wraz z otaczającymi je kompleksami leśnymi (RozPORZĄDZENIE... 1988). Jego powierzchnia wynosi ponad 15 tysięcy hektarów, z czego niemal $63 \%$ stanowią ekosystemy leśne. Przeważają tu bory sosnowe i mieszane, rzadziej występują grądy, a wzdłuż cieków i jezior tworzą się wąskie pasy lasów łęgowych 
i olsowych (KRZYSZTofiak 2010). Lasy wigierskie, pomimo kilkusetletniej eksploatacji, w wielu miejscach zachowały puszczański charakter. Znaczne zróżnicowanie siedliskowe Wigierskiego PN sprawia, że jest to obszar cechujący się dużym bogactwem gatunkowym zwierząt, grzybów i roślin, w tym również mszaków (FAŁTYNOWICZ 1994, KRZYSZTOFIAK 2010, WIERZCHOLSKA i in. 2010).

Brioflora Wigierskiego PN należy do dość dobrze poznanych, a doniesienia o mchach i wątrobowcach $z$ tego obszaru pochodzą $z$ licznych prac $z$ lat 60.-80. XX wieku (Rejment-Grochowska \& MickieWICZ 1962, MickIEWICZ i in. 1963, GoCŁAWSKA 1966, Bloch i in. 1979, Karczmarz \& Sokołowski 1981). Ważnym opracowaniem była również dokumentacja briologiczna wykonana przed utworzeniem parku narodowego wokół jeziora Wigry (Karczmarz \& SoKOŁOWSKI 1985). Podsumowaniem wszystkich danych historycznych połączonych $z$ najnowszą inwentaryzacją mszaków były badania prowadzone $\mathrm{w}$ latach 2008-2009. Stwierdzono wówczas, że flora mchów Wigierskiego PN liczy 229 taksonów (226 gatunków i 3 odmiany; Wierzcholska i in. 2010).

W latach 2017-2019 w ramach projektu „Drzewa centrami różnorodności biologicznej organizmów zarodnikowych w lasach" przeprowadzono badania brioflory epifitycznej czterech gatunków drzew: dębu szypułkowego, topoli osiki, klonu zwyczajnego i świerka pospolitego (FAtTYNOWicz i in. 2017, 2018a, b, 2019). Pionowe rozmieszczenie epifitów badano od podstawy drzew aż po ich korony. W wyniku wykonanych eksploracji terenowych, $z$ wykorzystaniem sprzętu alpinistycznego, udało się stwierdzić pięć gatunków mchów nowych dla Wigierskiego PN.W niniejszej pracy zaprezentowano ich wykaz wraz z charakterystyką siedliskową.

\section{MATERIAŁ I METODY}

Badaniami objęto 175 drzew (60 dębów szypułkowych Quercus robur, 60 topoli osik Populus tremula, 40 klonów zwyczajnych Acer platanoides i 15 świerków Picea abies) rosnących $\mathrm{w}$ grądzie subkontynentalnym Tilio cordatae-Carpinetum betuli Tracz. 1962 oraz w subkontynentalnym borze mieszanym Serratulo-Pinetum J. Mat. 1981. Materiał zbierano, z wykorzystaniem metod wspinaczkowych, z pni, konarów (o średnicy większej od $4 \mathrm{~cm}$ ) oraz $z$ gałęzi. Na każdym $z$ drzew badania prowadzono $\mathrm{w}$ obrębie następujących stref wysokościowych: I - 0-2 m, II - 2-6 m, III - 6-10 m, IV - 10-14 m, V - 14-18 m, VI - 18-22 m, VII - 22$26 \mathrm{~m}$ (FatTyNowicz i in. 2017, 2018a, b, 2019). Gatunki $\mathrm{w}$ wykazie zestawiono $\mathrm{w}$ porządku alfabetycznym. Nazewnictwo przyjęto za Ochyrą i in. (2003). Kategorie zagrożenia wyróżniono na podstawie obowiązującej czerwonej listy (ŻARNOWIEC i in. 2004).

\section{WYKAZ GATUNKÓW}

Dla każdego taksonu podano nazwę łacińską, polską, stanowisko (kwadrat ATMOS, lokalizacja, oddział, współrzędne GPS) oraz krótką charakterystykę siedliska.

Skróty: S-P - Serratulo-Pinetum, T-C - Tilio cordatae-Carpinetum betuli; gem. - z rozmnóżkami; spor. - ze sporofitami; WPN - Wigierski Park Narodowy; wydz.. - wydzielenie, !! - gatunek ściśle chroniony; kategoria zagrożenia gatunku w Polsce: E - wymierający, $\mathbf{R}$ - rzadki.

Dicranoweisia cirrata (Hedw.) Lindb. - kędzierzawiec wąsaty - Bg10: płd.-wsch. część WPN, w pobliżu miejscowości Studziany Las, wydz. 355f, $54.02234^{\circ} \mathrm{N}, 23.21809^{\circ} \mathrm{E}$, w borze mieszanym $S-P$, na gałązkach świerka pospolitego w VI strefie; gem.

Homomallium incurvatum (Schrad. ex Brid.) Loeske nibyrokiet skalny - Bf19: płn.-zach. część WPN, na południe od wsi Zamościska, wydz. 107t, $54.06223^{\circ} \mathrm{N}, 23.0514^{\circ} \mathrm{E}, \mathrm{w}$ grądzie $T-C$, na pniu i konarze osiki w III strefie; spor.

Orthotrichum pulchellum Brunt. - szurpek śliczny - Bg10: zachodnia część WPN, w pobliżu półwyspu Łapa na jeziorze Wigry, wydz. 211b, $54.0340167^{\circ} \mathrm{N}, 23.1416667^{\circ} \mathrm{E}, \mathrm{w}$ borze $S-P$, na dębie szypułkowym na gałązkach w II strefie; spor.; Bf19: w zachodniej części WPN w pobliżu Sobolewa, wydz. $100 \mathrm{~d}, 54.05101^{\circ} \mathrm{N}, 23.02127^{\circ} \mathrm{E}$; w grądzie $T$-C, na klonie zwyczajnym na gałązkach w III strefie; spor.

Serpoleskea subtilis (Hedw.) Loeske - nitecznik delikatny - Bf19: na zachód od miejscowości Zamościska, wydz. $94 \mathrm{~b}, 54.06755^{\circ} \mathrm{N}, 23.03553^{\circ} \mathrm{E}$, $\mathrm{w}$ grądzie $T-C$, na topoli osice na pniu w III strefie; w pobliżu miejscowości Zamościska, wydz. $107 \mathrm{t}, 54.06223^{\circ} \mathrm{N}, 23.05145^{\circ} \mathrm{E}, \mathrm{w}$ grądzie $T-C$, na topoli osice na pniu i konarze w III strefie; Bf09: na wschód od miejscowości Huta, wydz. 38i, $54.104106^{\circ} \mathrm{N}, 23.027992^{\circ} \mathrm{E}, \mathrm{w}$ grądzie $T-C$, na klonie zwyczajnym na pniu w II strefie; w pobliżu leśniczówki Gawarzec, wydz. 127c, 54.031297º N, $23.024532^{\circ} \mathrm{E}$, w grądzie $T-C$, na klonie zwyczajnym na pniu w I strefie; na płn.-zach. od miejscowości Bryzgiel, wydz. $382 \mathrm{~b}, 54.008092^{\circ} \mathrm{N}, 23.037946^{\circ} \mathrm{E}$, w grądzie $T-C$, na klonie zwyczajnym na pniu w III i IV strefie, $\mathbf{R}$.

!! Zygodon rupestris Schimp. ex Lorentz - zrostniczek skalny - Bf 19: w centralnej części WPN, w pobliżu Małego Sucharka Dembowskich, wydz. 145c, $54.03597^{\circ} \mathrm{N}, 23.06055^{\circ} \mathrm{E}, \mathrm{w}$ borze $S-P$, na pniu dębu szypułkowego w I strefie, gem., E. 


\section{UWAGI KONCOWE}

Przeprowadzone badania rozszerzyły listę mchów znanych z Wigierskiego PN o pięć nowych gatunków. Większość z nich to taksony rzadkie w skali naszego kraju. Szczególnie cenne było stwierdzenie obecności Zygodon rupestris oraz Serpoleskea subtilis, które znajdują się na czerwonej liście (ŻARNowIEC i in. 2004). Mchy te są uważane za relikty puszczańskie, a ich występowanie jest ograniczone wyłącznie do kompleksów leśnych cechujących się wysokim stopniem naturalności (CieśLIŃSKI i in. 1996, Stebel \& ŻARNoWIEC 2014, 2017). Interesujące jest również odnotowanie Dicranoweisia cirrata oraz Orthotrichum pulchellum. W przypadku obu tych taksonów w ostatnim czasie obserwuje się wzrost liczby stanowisk w całej Polsce (m.in. Stebel \& Plášek 2001, Stebel \& Smoczyk 2017, RusińsKa i in. 2018, Fudali \& ŻoŁNIERz 2019). W trakcie badań stwierdzono również występowanie Neckera pennata, która jest nowym gatunkiem dla Wigierskiego PN, ale stanowiska tego taksonu zostały zestawione $\mathrm{w}$ oddzielnej publikacji (GóRsKI $\mathrm{i}$ in. 2020). Obecnie liczba taksonów mchów występujących na obszarze Wigierskiego PN wynosi 235.

Większość gatunków przedstawionych w powyższym wykazie została odnotowana w wysokich partiach pni i koron - siedliskach $z$ reguly niedostępnych $\mathrm{w}$ trakcie tradycyjnych badań flory. Pozwala to sądzić, że liczba stanowisk tych taksonów może być większa oraz że siedliska te mogą kryć kolejne gatunki mchów, nieznane jeszcze $z$ tego terenu.

\section{PODZIĘKOWANIA}

Badania dofinansowano ze środków funduszu leśnego, przekazanych przez Lasy Państwowe w ramach Umowy zawartej pomiędzy Państwowym Gospodarstwem Leśnym Lasy Państwowe a Wigierskim Parkiem Narodowym Nr EZ.0290.1.20.2019 (działanie nr 36).

\section{LITERATURA}

Bloch M., Karczmarz K., SokoŁowski A.W. (1979): Nowe dane do flory mszaków północno-wschodniej Polski. II. Annales Universitatis Mariae Curie-Skłodowska, Lublin-Polonia, Sectio C, Vol. 34(5): 47-53.

Cieśliński S., Czyżewska K., Faliński J.B., Klama H., MuŁENKO W., ŻARNOWIEC J. (1996): Relicts of the primeval (virgin) forest. Relict phenomena. W: J.B. Faliński, W. Mułenko (red). Cryptogamous plants in the forest communities of Białowieża National Park. Functional groups analysis and general synthesis (Project Crypto 3). Phytocoenosis 8 (N. S.), Archivum Geobotanicum 6: 197-216.
FAŁTYNowicz W. (red.) (1994): Porosty Wigierskiego Parku Narodowego. Parki Narodowe i Rezerwaty Przyrody 13(3): 9-28.

Faetynowicz W., Górski P., Halama M., Kowalewska A., Staniaszek-Kik M., Faetynowicz H., Patejuk K., Piegdoń A. (2017): Raport z realizacji projektu pt. Drzewa centrami różnorodności biologicznej organizmów zarodnikowych w lasach - studium porównawcze na przykładzie Wigierskiego Parku Narodowego. Etap I: organizmy zarodnikowe na dębach szypułkowych Quercus robur. Maszynopis. Wigierski Park Narodowy, Krzywe.

Faetynowicz W., Górski P., Halama M., Kowalewska A., Staniaszek-Kik M., Faltynowicz H., Patejuk K., Piegdoń A. (2018a): Raport z realizacji projektu pt. Drzewa centrami różnorodności biologicznej organizmów zarodnikowych w lasach - studium porównawcze na przykładzie Wigierskiego Parku Narodowego. Etap II: organizmy zarodnikowe na topolach osikach Populus tremula. Maszynopis. Wigierski Park Narodowy, Krzywe.

Fattynowicz W., Kowalewska A., FatTynowicz H., Piegdoń A., Patejuk K., Górski P., Halama M., StaniASZEK-KIK M. (2018b): Epiphytic lichens of Quercus robur in Wigry National Park (NE Poland). Steciana 22(1): 19-27. doi:10.12657/steciana.022.002.

FaŁtynowicz W., Staniaszek-KiK M., Halama M., Górski P., Kowalewska A., Faetynowicz H., Patejuk K., Piegdoń A., Pencakowski B., Lenarczyk J., Panek E. (2019): Raport z realizacji projektu pt. Drzewa centrami różnorodności biologicznej organizmów zarodnikowych w lasach - organizmy zarodnikowe na klonie pospolitym Acer platanoides oraz świerku pospolitym Picea abies. Maszynopis. Wigierski Park Narodowy, Krzywe.

FudAli E., ŻoŁnIERZ L. (2019): Epiphytic bryophytes in urban forests of Wrocław (SW Poland). Biodiversity Research and Conservation 53: 73-83.

GocŁAwsKa D. (1966): Materiały do flory mszaków Puszczy Augustowskiej. Część 1. Mszaki nadleśnictwa: Balinka i Suwałki. Fragmenta Floristica et Geobotanica 12(4): 451-466.

Górski P., Romański M., Staniaszek-Kik M., WierzCHOlska S., Smoczyk M., Koczur A., Ociepa A.M. (2020): Rejestr nowych stanowisk mszaków występujących w Polsce, 1. Wiadomości Botaniczne (w druku).

Karczmarz K., SokoŁowski A.W. (1981): Nowe dane do flory mszaków północno-wschodniej Polski. III. Annales Universitatis Mariae Curie-Skłodowska, Sectio C, Biologia Vol. 36(11): 125-133.

KarczMARz K., SoKoŁOWski A.W. (1985): Brioflora projektowanego Wigierskiego Parku Narodowego Annales Universitatis Mariae Curie-Skłodowska. Sectio C, Biologia Vol. 40(18): 193-213.

KrzysztofiaK L. (red.) (2010): Śluzowce Myxomycetes, grzyby Fungi i mszaki Bryophyta Wigierskiego Parku Narodowego. Przyroda Wigierskiego Parku 
Narodowego. Stowarzyszenie „Człowiek i Przyroda", Suwałki.

Mickiewicz J., Rejment-Grochowska I., Sobotka D. (1963): Materiały do flory mszaków Suwalszczyzny. Część 2. Fragmenta Floristica et Geobotanica 9(2): 257-274.

Ochyra R., ŻARNOWIEC J., BednAREK-Ochyra H. (2003): Census catalogue of Polish mosses. Biodiversity of Poland. Vol. 3. W. Szafer Institute of Botany, Polish Academy of Sciences, Kraków.

Rejment-Grochowska I., Mickiewicz J. (1962): Materiały do flory mszaków Suwalszczyzny. Fragmenta Floristica et Geobotanica 8(1): 3-22.

RozPORZĄDZENIE Rady Ministrów z dnia 27 czerwca 1988 r. w sprawie utworzenia Wigierskiego Parku Narodowego. (1988). Dz.U. 1988 nr 25, poz. 173.

Rusińska A., KarpiŃski T.M., Adamczak A. (2018): 1. Dicranoweisia cirrata (Hedw.) Milde. W: P. Górski, A. Rusińska (red). New distributional data on bryophytes of Poland and Slovakia, 14. Steciana 22(2): 51-52. doi:10.12657/steciana.022.007.

Stebel A., Plášek V. (2001): Dicranoweisia cirrata and Orthodicranum tauricum (Musci) in the Polish and
Czech part of Upper Silesia - Distribution and ecology. Natura Silesiae Superioris 5: 21-31.

Stebel A., Smoczyк M. (2017): Further spreading of the moss Orthotrichum pulchellum in Poland. Herzogia 30: 296-299.

Stebel A., ŻARnowiec J. (2014): Gatunki puszczańskie we florze mchów Bieszczadzkiego Parku Narodowego (Karpaty Wschodnie). Roczniki Bieszczadzkie 22: 259-277.

Stebel A., Żarnowiec J. (2017): The Moss Genus $Z y$ godon (Orthotrichaceae) in Poland - Distribution, Ecological Preferences and Threats. Cryptogamie, Bryologie 38(3): 231-251.

Wierzcholska S., Plášek V., Krzysztofiak A. (2010): Mszaki (Bryophyta). W: L. Krzysztofiak (red.). Śluzowce Myxomycetes, grzyby Fungi i mszaki Bryophyta Wigierskiego Parku Narodowego. Przyroda Wigierskiego Parku Narodowego. Stowarzyszenie „Człowiek i Przyroda”, Suwałki: 229-298.

Żarnowiec J., Stebel A., Ochyra R. (2004): Threatened moss species in the Polish Carpathians in the light of a new Red list of mosses in Poland. W: A. Stebel, R. Ochyra (red.). Bryological studies in the Western Carpathians. Sorus, Poznań: 9-28. 